\title{
Investigation of Sediments Causing Damage to Water Meters in a Large Drinking Water Distribution System
}

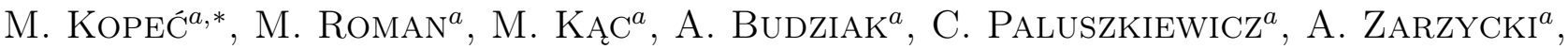

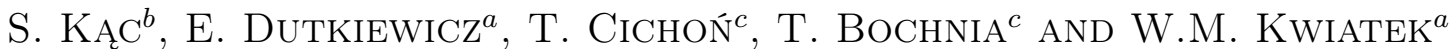 \\ ${ }^{a}$ Institute of Nuclear Physics, Polish Academy of Sciences, PL-31342 Krakow, Poland \\ ${ }^{b}$ AGH University of Science and Technology, PL-30059 Krakow, Poland \\ ${ }^{c}$ Municipal Water Supply and Sewage in Krakow, PL-30106 Krakow, Poland
}

\begin{abstract}
Preliminary studies on the sediments collected from water meters of Krakow water supply system were performed in the cooperation with the Municipal Water Supply and Sewage. Creation and deposition of sediments on the measuring devices installed in the water supply system is a serious technological and economical problem for water companies, defectively operating for this reason water meters must be replaced. It is evident that knowledge of the chemical and phase composition of sediments is an important step towards resolving the problem of impurities in water supply systems. Four different samples of sediments, coming from water meters, were investigated using the proton-induced X-ray emission, the X-ray diffraction, the Fourier transform infrared and Raman spectroscopy. The X-ray methods revealed presence of amorphous and fine-crystalline phases as well as high content of iron-based compounds. As a crystalline phase, the most frequently appeared: goethite, lepidocrocite, iron oxides (hematite, maghemite, magnetite), calcium carbonate, and quartz. In one of the samples, the nanocrystalline phase was found and identified as hydrous iron oxyhydroxide ferrihydrite. Vibrational spectroscopy methods confirmed the composition of crystalline phases as well as enabled to estimate the abundance of amorphous phase in samples.
\end{abstract}

DOI: 10.12693/APhysPolA.133.296

PACS/topics: 89.60.-k, 78.70.En, 61.05.cp, 82.80.-d, 82.80.Gk

\section{Introduction}

In a great number of cities in the world water supply network (WSN) being a part of the drinking water distribution systems (DWDSs) is made of steel and cast iron. Corrosion of water pipes results in the appearance of deposits which change the physical and chemical properties of the water and make its organoleptic properties become worse. Corrosion of steel parts having the direct contact with drinking water can also stimulate processes of microbiological corrosion $[1-3]$ and negatively influences the hydrodynamic properties of WSN. It results in the need of frequent flushing of WNS and the increase of WSN failure. Apart from negative influence on health aspects, this problem should be also considered in economic terms.

Morphology and composition of corrosion scales and deposits occurring in DWDSs have been studied so far by many research groups [4-10]. Corrosion scales usually include inorganic iron-based compounds such as iron(III) oxide-hydroxides (goethite $(\alpha-\mathrm{FeOOH}), \quad$ akaganeite $(\beta$-FeOOH $), \quad$ lepidocrocite $(\gamma-\mathrm{FeOOH}))$, iron oxides (hematite $\alpha-\mathrm{Fe}_{2} \mathrm{O}_{3}$ ), maghemite $\left(\gamma \mathrm{Fe}_{2} \mathrm{O}_{3}\right)$, magnetite $\left.\left(\mathrm{Fe}_{3} \mathrm{O}_{4}\right)\right)$, green

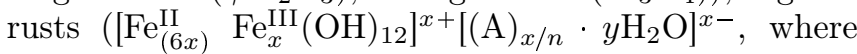
$x=0.9-4.2, \mathrm{~A}$ is an $n$-valent anion - typically $\mathrm{CO}_{3}^{2-}$, $\mathrm{Cl}^{-}$or $\mathrm{SO}_{4}^{2-}$, and $y=2$ to 4 ), iron(II) hydroxide $\left(\mathrm{Fe}(\mathrm{OH})_{2}\right)$, and iron sulfides (e.g. pyrrhotite $\left(\mathrm{Fe}_{1-x} \mathrm{~S}\right)$ ).

*corresponding author; e-mail: marek.kopec@ifj.edu.pl
Some of the components are unstable such as green rusts, which rapidly oxidize in the presence of air $[10,11]$. On the other hand, widely occurring two-line ferrihydrite, a poorly crystalline $\mathrm{Fe}(\mathrm{III})$ oxyhydroxide of the nominal chemical formula $5 \mathrm{Fe}_{2} \mathrm{O}_{3} \cdot 9 \mathrm{H}_{2} \mathrm{O}$ [12], under oxidative aqueous conditions gradually transforms to more crystalline and stable $\mathrm{Fe}(\mathrm{III})$ oxides: goethite and hematite $[13,14]$. Furthermore, water sediments can also contain quartz, sulfates, calcium carbonates, etc.

Chemical and phase composition of corrosion scales and deposits has been determined using different methods such as elemental analysis $[4,15]$, X-ray diffraction (XRD) $[6,9,10]$, scanning electron microscopy (SEM) $[8,9,10,15]$, and vibrational spectroscopy [15]. The occurrence of water sediments is the main reason of water meters failure in DWDSs. Progressively appearing sediments are a great technological problem. Sediments slow water meters down or even stop their mechanisms. As a result, water meters measure lower volume of water than flows through the WSN in reality. It induces much more frequent exchange of water meters than it results from legalization regulations of meter devices. The need to replace faulty water meters is a serious economic problem for water supply companies [16].

Krakow DWDS of over $2100 \mathrm{~km}$ WSN length supplies ca. $170000 \mathrm{~m}^{3}$ of water to citizens every day. Approximately 1000 water meters of 20 to $100 \mathrm{~mm}$ diameter is exchanged and investigated in this system annually due to suspicion of their incorrect operation, i.e. water meter stoppage or measuring too low water volume compared with previous readout periods. In most cases, 
water meters failure is caused by corrosion scales, which are formed in WSN before the individual water meters and transported to the water meters by water stream. Another reason of water meter stoppage can be a relatively small amount of calcium carbonate-type sediment which crystallizes on the water meter parts. Even small amounts of the sediment located in a contact surface of a rotor axis and a bearing can result in water meter failure. Significant number of all exchanged devices corresponds to water meters that are not stopped, but the presence of sediments on moving parts (rotor blade, bearing) causes the increase of friction forces and false water measurements. As a result, the water meter has to be disassembled and exchanged with a new one (water meters cannot be repaired) [16].

The aim of this work is to investigate, for the first time, chemical and phase composition of the sediments deposited on measuring parts of water meters disassembled from the Krakow DWDS. Due to high costs of exchange of faulty water meters in DWDSs, it is of great importance to increase our knowledge of sediments, which destroy water meters. Our analysis was performed using vibrational spectroscopies and X-ray methods to gain deeper insight into sediments composition and, as a consequence, to enhance our understanding about sediments formation.

\section{Materials and methods}

Four samples of sediments (S1-S4) were collected from various water meters of the Krakow DWDS, which have been removed due to damage or malfunction. Samples $\mathrm{S} 1$ and S2 were collected from water meters of $80 \mathrm{~mm}$ diameter, their measuring parts have been stopped by a large amount of deposited corrosion scales of brown-red color. On the other hand, a sediment deposited on rotor blades of $40 \mathrm{~mm}$ water meter was assigned as sample S3, whereas a gray-brown sediment covering a rotor and an inner part of a water meter of $100 \mathrm{~mm}$ diameter, which was not stopped, but exchanged due to false water measurements, was assigned as sample S4.

The phase analysis of sediments was performed by Xray diffraction (XRD) technique. The XRD measurements were carried out using a Panalytical X'Pert Pro diffractometer with $\mathrm{Cu} K$ radiation operated at $40 \mathrm{kV}$ and $30 \mathrm{~mA}$. Measurements were carried out at room temperature. All the samples, during the measurements, were placed on the zero-background silicon plate. The X'Pert HighScore ver 2.1 programs and ICDD PDF-2 database were used to identify the X-ray patterns.

Elemental composition of the samples was determined by the use of EDS technique. The EDS spectra were measured using HITACHI S-3500N microscope equipped with secondary electron detector and NORAN 986B1SPS EDS analyzer with acceleration voltage of $10 \mathrm{kV}$.

Trace elements content was established by means of proton-induced X-ray emission (PIXE) technique. The PIXE analysis was done with the use of $2 \mathrm{MeV}$ proton microbeam of linear, electrostatic Van de Graaff accelerator (INP PAN, Krakow). The proton beam diameter was $20 \mu \mathrm{m}$. Spectra were collected by semiconductor $\mathrm{Si}(\mathrm{Li})$ detector with $190 \mathrm{eV}$ of FWHM for Mn $K_{\alpha}$ line and analyzed using GUPIX program [17], PIXE measurements were also done in order to confirm EDS results.

The Fourier transform infrared (FT-IR) spectra were measured using a Bruker Vertex 70v spectrometer with an OPUS 7.5 system in a transmission mode. The samples were well mixed into $\mathrm{KBr}$ powder, pulverized, and prepared in the form of discs. The spectra were measured with a spectral resolution of $4 \mathrm{~cm}^{-1}$ in the range from $4000 \mathrm{~cm}^{-1}$ to $200 \mathrm{~cm}^{-1}$.

The Raman spectra were recorded using a Renishaw InVia Raman spectrometer equipped with an optical confocal microscope, air-cooled lasers emitting at 532, 633, and $785 \mathrm{~nm}$, and an EMCCD detector thermoelectrically cooled to $-100^{\circ} \mathrm{C}$. The dry Leica N PLAN EPI (50x, NA $0.75)$ objective was used. The power of the laser at the sample position was $c a$. $0.03-0.2 \mathrm{~mW}$ depending on the applied laser. The 10 scans with integration time of $20 \mathrm{~s}$ and a resolution of $0.5 \mathrm{~cm}^{-1}$ were collected and averaged. The spectrometer was calibrated using the Raman scattering line generated by an internal silicon plate. The samples were put directly on aluminum slides. A laser spot was focused on the sediment surface and then the measurement was performed.

\section{Results and discussion}

Optical microscope images of samples S1-S4 (Figs. 1A, 2A, 3A, 4A) indicate high heterogeneity of the collected sediments. Since chemical composition of the samples seems to be complex, only application of complementary analytical methods will provide a full description of sediment components.

The elemental composition measurements were performed at different places of the sample and averaged. Analyzed sample S1 (Fig. 1B) revealed a high content of iron (65-70\%) and relatively low abundance of silicon (1.5-3.5\%). Sample S1 contained also traces of sulfur and calcium.

XRD pattern of sample S1 is presented in Fig. 1C. It shows several peaks suggesting pure crystalline phases and relatively large background indicating significant contribution of amorphous phase. Contribution of crystalline and amorphous phases was estimated of the similar level. Identified peaks proved the presence of goethite and lepidocrocite with contributions equal to $71 \%$ and $29 \%$, respectively.

Chemical composition of both amorphous phase and the crystalline phase can be determined by vibrational spectroscopy methods. FT-IR spectrum of sample S1 is shown in Fig. 1D. As can be seen, the spectrum exhibits characteristic bands of iron(III) oxide-hydroxides and iron oxides. Indeed, hematite and goethite bands can be observed in the region from $250 \mathrm{~cm}^{-1}$ to $500 \mathrm{~cm}^{-1}$ with maxima at $285 \mathrm{~cm}^{-1}, 430 \mathrm{~cm}^{-1}$ (goethite) and $460 \mathrm{~cm}^{-1}$ 


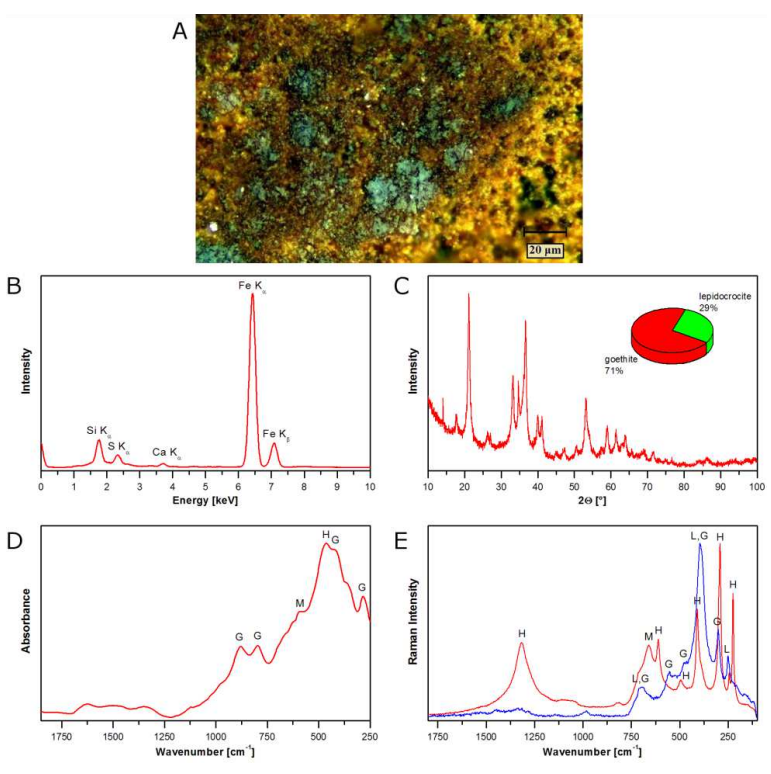

Fig. 1. Sample S1: optical image (A), PIXE spectrum (B), XRD pattern (C), FT-IR spectrum (D), and Raman spectra (E) $(\mathrm{H}$ - hematite, $\mathrm{M}$ - magnetite, $\mathrm{G}$ goethite, L - lepidocrocite.
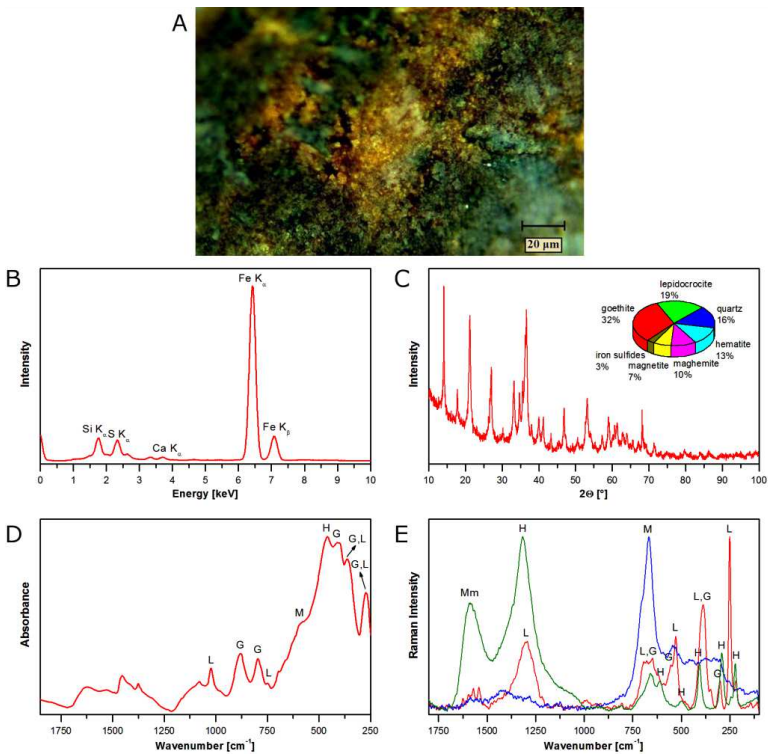

Fig. 2. Sample S2: optical image (A), PIXE spectrum (B), XRD pattern (C), FT-IR spectrum (D), and Raman spectra $(\mathrm{E})(\mathrm{H}$ - hematite, $\mathrm{M}$ - magnetite, $\mathrm{Mm}$ - maghemite, $\mathrm{G}$ - goethite, $\mathrm{L}$ - lepidocrocite).

(hematite) [18-20]. A shoulder band at $580 \mathrm{~cm}^{-1}$ can be assigned to magnetite [19-21], however, both hematite and goethite exhibit absorption in that region as well. Additionally, a characteristic doublet with maxima at $800 \mathrm{~cm}^{-1}$ and $880 \mathrm{~cm}^{-1}$ comes from goethite $[18,19]$.

Due to mentioned heterogeneity, the Raman spectra were collected from various places along the sample. Figure 1E shows two representative spectra from sample S1. A red spectrum reveals characteristic bands of hematite and magnetite, whereas the blue one confirms
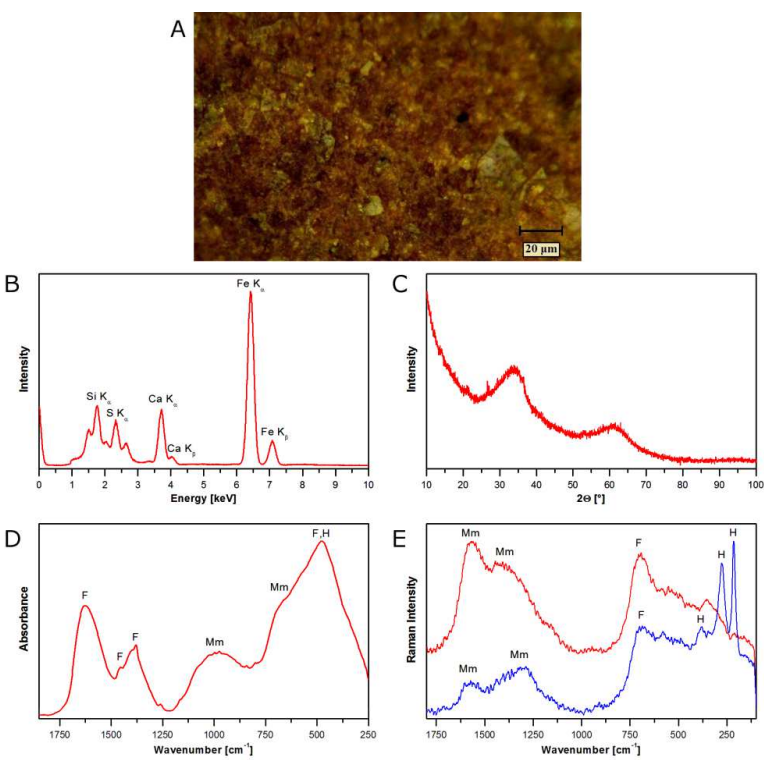

Fig. 3. Sample S3: optical image (A), PIXE spectrum (B), XRD pattern (C), FT-IR spectrum (D), and Raman spectra (E) $(\mathrm{H}$ - hematite, $\mathrm{Mm}$ - maghemite, $\mathrm{F}$ - ferrihydrite).
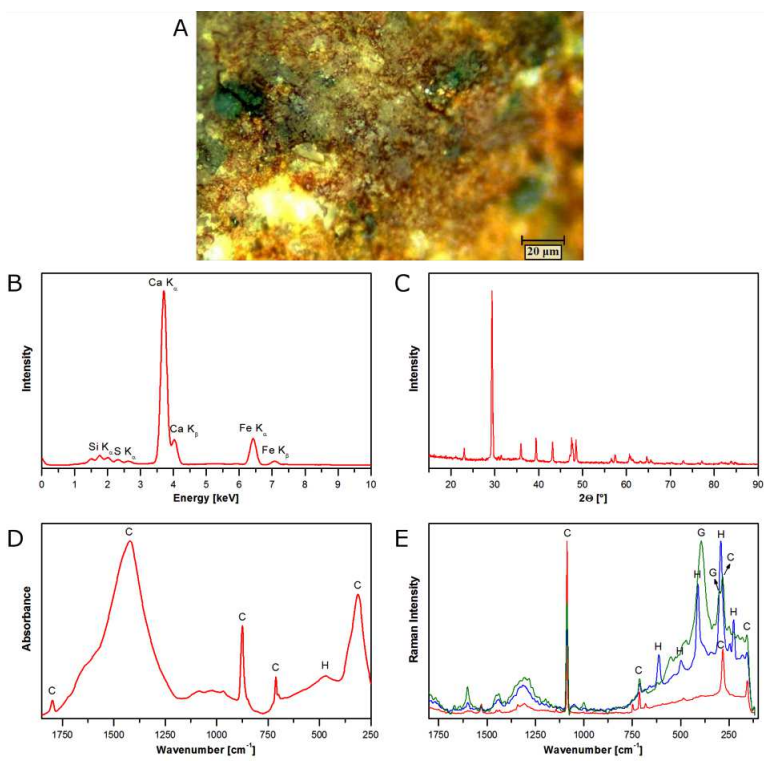

Fig. 4. Sample S4: optical image (A), PIXE spectrum (B), XRD pattern (C), FT-IR spectrum (D), and Raman spectra $(\mathrm{E})(\mathrm{H}$ - hematite, $\mathrm{C}$ - calcite, $\mathrm{G}$ goethite).

the presence of goethite and lepidocrocite. Indeed, bands with maxima at $c a .225,245,290,410,495,610$, and $1315 \mathrm{~cm}^{-1}$ observed in the first spectrum are characteristic for hematite found in corrosion scales [15, 22, 23]. On the other hand, a broad band at $660 \mathrm{~cm}^{-1}$ comes from magnetite. The second spectrum exhibits completely different pattern with the most intense band at $395 \mathrm{~cm}^{-1}$, which can be assigned to goethite. However, a slight broadening on the low-wave number side of this band 
suggests also the presence of lepidocrocite. Other bands observed in the blue Raman spectrum can be assigned either to goethite $\left(300 \mathrm{~cm}^{-1}\right.$ and $\left.550 \mathrm{~cm}^{-1}\right)$ or lepidocrocite $\left(250 \mathrm{~cm}^{-1}\right)[15,22-25]$. A band at $695 \mathrm{~cm}^{-1}$ comes from both mentioned oxide-hydroxides.

Elemental composition of sample $\mathrm{S} 2$ is very similar to the composition of sample S1. According to PIXE (Fig. 2B) and EDS spectra (data not shown), sample S2 contains mainly iron (ca. 60-75\%) and small amount of silicon (1.5-3\%) and sulfur (1\%). Moreover, a few elements such as calcium and chlorine were found with concentrations lower than $1 \%$.

XRD pattern of sample S2 (Fig. 2C) shows many peaks suggesting a very complex chemical composition of the crystalline phase. Indeed, several compounds were identified in this phase including iron oxide-hydroxides (goethite $(32 \%)$ and lepidocrocite $(19 \%)$, iron oxides (hematite $(13 \%)$, maghemite $(10 \%)$, magnetite $(7 \%)$, and quartz (16\%). Furthermore, sample S2 contains probably non-stoichiometric iron sulfides $(3 \%$ in the crystalline phase). Similarly to sample S1, XRD results reveals significant contribution of amorphous phase, this was estimated in this sample to be equal to $60 \%$.

FT-IR spectrum of sample S2 (Fig. 2D) exposes mainly bands characteristic for iron oxide-hydroxides and iron oxides. The most intense band in the spectrum $\left(460 \mathrm{~cm}^{-1}\right)$ can be assigned to hematite $[18,19]$. Other bands in this region come from goethite $410 \mathrm{~cm}^{-1}$ ) or both goethite and lepidocrocite $\left(270 \mathrm{~cm}^{-1}\right.$ and $360 \mathrm{~cm}^{-1}$ ) [18, 19]. As it was shown for sample S1, the presence of goethite can be also confirmed by two bands with maxima at $800 \mathrm{~cm}^{-1}$ and $880 \mathrm{~cm}^{-1}[18,19]$. Furthermore, the FT-IR spectrum exhibits characteristic bands of lepidocrocite at $750 \mathrm{~cm}^{-1}$ and $1020 \mathrm{~cm}^{-1}$. As previously, a shoulder band at $580 \mathrm{~cm}^{-1}$ can be assigned to magnetite [19-21]. In contrast to sample S1, FT-IR spectrum of sample $\mathrm{S} 2$ shows several bands of significant intensity in the region from $1300 \mathrm{~cm}^{-1}$ to $1700 \mathrm{~cm}^{-1}$. These bands come probably from stretching and bending vibrations of methylene and methyl groups present in organic compounds.

The Raman spectra collected from various places along the sample S2 show different shapes (Fig. 2E). A red spectrum exhibits characteristic bands of goethite and lepidocrocite. Thus, the most intense bands with maxima at 250,530 , and $1290 \mathrm{~cm}^{-1}$ come from lepidocrocite, whereas a band at $300 \mathrm{~cm}^{-1}$ and a shoulder at $555 \mathrm{~cm}^{-1}$ can be assigned to goethite. Other bands present in this spectrum $\left(390 \mathrm{~cm}^{-1}\right.$ and $\left.650 \mathrm{~cm}^{-1}\right)$ originate from both goethite and lepidocrocite $[15,22-25]$. The blue spectrum shows a broad intense band at $665 \mathrm{~cm}^{-1}$, which is characteristic for magnetite. Similarly to sample S1, bands characteristic for hematite can be observed in the green spectrum with maxima at 220, 245, 290, 405, 500, 610 , and $1315 \mathrm{~cm}^{-1}[15,22,24]$. Furthermore, magnetite occurrence can be proven by the presence of a band at $660 \mathrm{~cm}^{-1}$. However, this band shows a broadening towards higher wave numbers suggesting overlapping with another band, which together with a band at $1590 \mathrm{~cm}^{-1}$ come probably from maghemite [15, 22-25]. The presence of maghemite was also suggested in this sample by XRD studies (Fig. 2C).

$\mathrm{X}$-ray diffraction and spectroscopic analysis of deposits taken from samples S1 and S2 shows unequivocally that both samples contain mainly corrosion products of iron, i.e. iron(III) oxide-hydroxides and iron oxides. Indeed, goethite, lepidocrocite, hematite, maghemite, and magnetite were identified in these samples. Furthermore, $\mathrm{XRD}$ results confirmed the presence of quartz and iron sulfides in sample $\mathrm{S} 2$.

Sample S3 was collected from rotor blades of a water meter. Analysis of elemental composition of sample S3 (Fig. 3B) indicates iron (ca. 60\%) as a main element. Iron is accompanied by calcium (4-5\%), silicon (ca. $2.5 \%)$, and chlorine (ca. 1\%). Traces of phosphorus and sulfur were found in this sample as well.

XRD pattern of sample S3 (Fig. 3C) shows only two broad peaks, which can be assigned to ferrihydrite. It is a poorly ordered fine crystallized hydrous iron oxide commonly present in water sediments [26, 27].

The occurrence of ferrihydrite was confirmed by FT-IR and Raman spectroscopy (Fig. 3D and 3E, respectively). FT-IR spectrum of sample S3 (Fig. 3D) shows characteristic bands found in ferrihydrite spectrum $(475,1380$, 1450 , and $1625 \mathrm{~cm}^{-1}$ ) as well as broad bands assigned to maghemite (a shoulder of the $475 \mathrm{~cm}^{-1}$ band and overlapping bands in the region of $850-1200 \mathrm{~cm}^{-1}$ ) [1820]. As it has been proven in literature [26], formation of maghemite can result from thermal transformation of ferrihydrite during the measurement. The final product of the transformation is hematite (not proved by the FT-IR spectrum). The Raman spectra (Fig. 3E) collected from sample S3 exhibit a characteristic band for ferrihydrite $\left(700 \mathrm{~cm}^{-1}\right)$, bands coming from maghemite $\left(1320 \mathrm{~cm}^{-1}\right.$ and $\left.1560 \mathrm{~cm}^{-1}\right)$ as well as bands assigned to hematite $\left(215,275\right.$, and $\left.385 \mathrm{~cm}^{-1}\right)$ [26]. A small shift of hematite bands in the Raman spectrum of sample S3 results from the laser power dependence of the hematite band positions noted previously in [22]. As can be seen, apart from most abundant ferrihydrite, the Raman spectra show both an intermediate product (maghemite) and the final one (hematite) of ferrihydrite thermal transformation.

Some sediment found on inner parts of a rotor (e.g. rotor axis) was collected and assigned as sample S4. PIXE (Fig. 4B) and EDS analysis of sample S4 show this sample to be rich in calcium (ca. 40\%) and iron (ca. 38\%). However, several other elements were found in this sample including silicon (1-2\%), phosphorus (1\%), and traces of sulfur, magnesium, manganese, and chlorine.

XRD pattern of sample S4 (Fig. 4C) shows a few narrow peaks suggesting a well-crystallized phase. Indeed, analysis of the peak positions revealed the presence of one component, which was identified as calcite.

Fingerprint region of FT-IR spectrum of sample S4 (Fig. 4D) shows a few bands with maxima at 310, 715, 
875,1420 , and $1800 \mathrm{~cm}^{-1}$. These bands are characteristic for calcite $[28,29]$ confirming very high concentration of this carbonate in the sample. Apart from calcite, sample S4 contains small amounts of iron oxides such as hematite demonstrated by the presence of a band at $470 \mathrm{~cm}^{-1}$ in the FT-IR spectra [18-20].

Raman spectra of sample S4 (Fig. 4E) reveal a very intense band at $1085 \mathrm{~cm}^{-1}$ assigned to calcite [30, 31]. Other characteristic bands of this compound can be found at 155,280 , and $710 \mathrm{~cm}^{-1}[30,31]$. As can be seen, the red spectrum is free from other components, whereas the blue and green ones show some additional signals. The blue spectrum exhibits, besides calcite, bands characteristic for hematite, i.e. 225, 245, 290, 410, 500, and $610 \mathrm{~cm}^{-1}[15,22,23]$. Additionally the green spectrum confirms the occurrence of goethite based on characteristic bands at $\mathrm{ca} .300 \mathrm{~cm}^{-1}$ and $395 \mathrm{~cm}^{-1}$ [15, 22-25].

X-ray and spectroscopic analysis of samples S3 and S4 show that their chemical composition differs not only from the previous samples (sample S1 and S2), but also between each other. Sample S3 contains mainly ferrihydrite, whereas sample $\mathrm{S} 4$ is rich in calcite. PIXE and EDS gave better insight into elemental composition, whereas XRD was useful for chemical analysis of the crystalline phase. Fortunately, both crystalline and amorphous phase can be investigated using vibrational spectroscopy methods, i.e. infrared and the Raman spectroscopy. Due to characteristic pattern in the vibrational spectra, corrosion products can be easily identified by these methods providing chemical data on the sediments composition. Information gathered from X-ray and spectroscopic methods gave us a full chemical description of the samples, which brought us closer to better understanding of sediments formation mechanisms.

\section{Conclusions}

Four sediments collected from water meters of the Krakow DWDS were measured using X-ray and vibrational spectroscopy methods in order to analyze their chemical and phase composition. Samples S1 and S2, deposited corrosion scales of brown-red color, were found to be rich in iron and contain similar level of amorphous phase and the crystalline one. Both samples consist mainly of corrosion products such as iron(III) oxidehydroxides and iron oxides. Significant amounts of quartz were detected in sample S2 as well. Sample S3, a sediment collected from rotor blades, was identified as ferrihydrite and poorly crystalline $\mathrm{Fe}(\mathrm{III})$ oxyhydroxide. However, thermal products of ferrihydrite transformation, hematite and maghemite, were additionally identified by vibrational spectroscopy. Finally, sample S4 was found to be rich in calcium and iron, which was confirmed by spectroscopic methods used in this study. XRD determined crystalline phase to contain calcite, whereas vibrational spectroscopic methods enabled identification of hematite and goethite as well. To sum up, X-ray and spectroscopic analysis of the samples revealed corrosion products as main components of the collected sediments with iron(III) oxide-hydroxides and iron oxides as most frequently occurring compounds. Only sample S4 was dominated by calcite coming from water hardness and accompanied by corrosion products. As can be seen, samples studied in this work showed high heterogeneity and diversity of chemical composition. Only application of different and complementary methods gives a powerful tool for chemical analysis of water sediments. Our work demonstrates the usefulness of X-ray and vibrational spectroscopy methods for full determination of phase and chemical composition of the sediments deposited on water meters. These methods can be successfully applied for further analyses to increase our understanding about sediments composition and mechanisms of their formation.

\section{Acknowledgments}

The research was performed using equipment purchased in the frame of the project co-funded by the Małopolska Regional Operational Programme Measure 5.1 Krakow Metropolitan Area as an important hub of the European Research Area for 2007-2013, project No. MRPO.05.01.00-12-013/15.

\section{References}

[1] O.H. Tuovinen, J.C. Hsu, Appl. Envir. Microbiol. 44, 761 (1982).

[2] L. Tuhela, L. Carlson, O.H. Tuovinen, Water Res. 26, 1159 (1992).

[3] I.B. Beech, Microbiol. Today 30, 115 (2003).

[4] J.P. Lin, M. Ellaway, R. Adrien, Corros. Sci. 43, 2065 (2001).

[5] P. Sarin, V.L. Snoeyink, J. Bebee, W.M. Kriven, J.A. Clement, Water Res. 35, 2961 (2001).

[6] P. Sarin, V.L. Snoeyink, J. Bebee, K.K. Jim, M.A. Beckett, W.M. Kriven, J.A. Clement, Water Res. 38, 1259 (2004).

[7] P. Sarin, V.L. Snoeyink, D.A. Lytle, W.M. Kriven, J. Envir. Eng. 130, 364 (2004).

[8] T.L. Gerke, J.B. Maynard, M.R Schock, D.L. Lytle, Corros. Sci. 50, 2030 (2008).

[9] C.Y. Peng, G.V. Korshin, R.L. Valentine, A.S. Hill, M.J. Friedman, S.H. Reiber, Water Res. 44, 4570 (2010)

[10] J. Swietlik, U. Raczyk-Stanislawiak, P. Piszora, J. Nawrocki, Water Res. 46, 1 (2012).

[11] J. Nawrocki, U. Raczyk-Stanislawiak, J. Swietlik, A. Olejnik, M.J. Sroka, Water Res. 44, 1863 (2010).

[12] J.L. Jambor, J.E. Dutrizac, Chem. Rev. 98, 2549 (1998).

[13] Y. Cudennec, A. Lecerf, J. Solid State Chem. 179, 716 (2006).

[14] S. Das, M.J. Hendry, J. Essilfie-Dughan, Envir. Sci. Technol. 45, 268 (2011).

[15] F. Yang, B. Shi, J. Gu, D. Wang, M. Yang, Water Res. 46, 5423 (2012). 
[16] T. Cichon, J. Krolikowska, Gaz, woda i technika sanitarna 3, 87 (2015), (in Polish).

[17] J.L. Campbell, N.I. Boyd, N. Grassi, P. Bonnick, J.A. Maxwell, Beam Interact. Mater. Atoms 268, 3356 (2010)

[18] A.U. Gehring, A.M. Hofmeister, Clays Clay Miner. 42, 409 (1994).

[19] J.F. Bell III, T.L. Roush, R.V. Morris, J. Geophys. Res. 100, 5297 (1995).

[20] I. Chamritski, G. Burns, J. Phys. Chem. B 109, 4965 (2005).

[21] L.V. Gasparov, D.B. Tanner, D.B. Romero, H. Berger, G. Margaritondo, L. Forró, Phys. Rev. B 62, 7939 (2000)

[22] D.L.A. de Faria, S. Venancio Silva, M.T. de Oliveira, J. Raman Spectrosc. 28, 873 (1997).

[23] M.A. Legodi, D. de Waal, Dyes Pigm. 74, 161 (2007).
[24] D. Neff, L. Bellot-Gurlet, P. Dillmann, S. Reguer, L. Legrand, J. Raman Spectrosc. 37, 1228 (2006).

[25] J. Monnier, L. Bellot-Gurlet, D. Baron, D. Neff, I. Guillot, P. Dillmann, J. Raman Spectrosc. 42, 773 (2011).

[26] L. Mazzetti, P.J. Thistlethwaite, J. Raman Spectrosc. 33, 104 (2002).

[27] Y. Jia, L. Xu, X. Wang, G.P. Demopoulos, Geochim. Cosmochim. Acta 71, 1643 (2007).

[28] F.A. Andersen, L. Brecevic, Acta Chem. Scandin. 45, 1018 (1991)

[29] L.L. Long, M.R. Querry, R.J. Belly, R.W. Alexander, Infrared Phys. 34, 191 (1993).

[30] G. Behrens, L.T. Kuhn, R. Ubic, A.H. Heuer, Int. J. Rapid Commun. 28, 983 (1995).

[31] C.G. Kontoyannis, N.V. Vagenas, Analyst 125, 251 (2000). 